\title{
Chemical titration method for Determination of Concentration of REO in Rare Earth Fluoride Melts
}

\author{
Xiaoping Zhu a, Shuchen Sun ${ }^{b}$, Chuan Liu c, Ganfeng Tu d \\ School of Metallurgy, Northeastern University, Shenyang 110819, China. \\ axiaopingzhu007@outlook.com, bsunsc@smm.neu.edu.cn, c755800346@qq.com, \\ dugf@smm.neu.edu.cn
}

Keywords: $\mathrm{REF}_{3}$-LiF, REO concentration, rare earth, molten salts, solubility.

\begin{abstract}
In the present study, chemical titration method for determination of concentration of REO in $\mathrm{REF}_{3}-\mathrm{LiF}-\mathrm{RE}_{2} \mathrm{O}_{3}$ melts was investigated. The melts with the composition of $40 \mathrm{~mol} \% \mathrm{REF}_{3}-$ $60 \mathrm{~mol} \% \mathrm{LiF}$ ( $\mathrm{RE}=\mathrm{La}$ and $\mathrm{Nd}$ ) was taken as object for illustrating the measurement of concentration and solubility of REO by the chemical titration method. Then the changing of REO concentration in $40 \mathrm{~mol}^{2} \mathrm{REF}_{3}-60 \mathrm{~mol} \% \mathrm{LiF}$ melts with electrolytic time in practical electrolysis production was studied. The concentration of REO decreases with the electrolytic time, and rate of the decreasing also declines with the electrolytic time. And the reasonable time interval for REO addition was recommended defining as $1.75 \mathrm{~h}$ which is very close to the empirical value $2 \mathrm{~h}$, This would also illustrate the reliability of chemical titration method on determination of concentration of REO in the melts.
\end{abstract}

\section{Introduction}

$\mathrm{REF}_{3}-\mathrm{LiF}-\mathrm{RE}_{2} \mathrm{O}_{3}$ is the most important electrolyte for producing rare earth metal and its alloys in modern industry [1-4]. The foundation of developing novel electrolysis technology and equipment are also based on the $\mathrm{REF}_{3}-\mathrm{LiF}-\mathrm{REO}$ molten salts system. Moreover, $\mathrm{REF}_{3}-\mathrm{LiF}$ molten salts are also very significant for their potential use in the extraction lanthanum (RE) elements from molten salts in the general frame of reprocessing nuclear wastes [5-7]. In the electrolysis process, $\mathrm{REF}_{3}-\mathrm{LiF}_{\text {acts }}$ as the solvent for the oxide, and REO is the actual consumption of the eletrolyte. So, REO need to be added continuously. Researches [8-9] found that the current efficiency increases with the increasing of the addition rate of REO. However, the low solubility of REO is the primary cause for forming the precipitation and even the slag at the bottom of the electrolytic cell which is terrible effect on the current efficiency in practical production. So the determination of REO concentration in $\mathrm{REF}_{3}-\mathrm{LiF}-$ REO melts is considered as an important process for establishing reasonable $\mathrm{RE}_{2} \mathrm{O}_{3}$ addition system and the time interval of addition.

In recent years, the solubility of REO in fluoride melts was widely researched [10-21]. It was found that the solubility was relatively low and the melts with high temperature and strong corrosiveness so that there were difficulties for accurate measuring the concentration of REO in fluoride melts. According to the published researches, the specific measurement methods for determining concentration of REO were chemical analysis, thermal analysis. What is more, the surface tension was related to concentration of REO in molten rare earth fluoride melts based on the recent reference on surface tension [22]. So, the determination of concentration of REO can be determined by surface tension and using relationship between surface tension and concentration of REO. In the present study, chemical titration method for determination of concentration of REO in $\mathrm{REF}_{3}$-LiF-REO melts was discussed.

\section{Experimental}

All of chemicals were analytical pure (Table 1), $\mathrm{REF}_{3}, \mathrm{LiF}$ and $\mathrm{REO}$ were dried before being used under the temperature of $150^{\circ} \mathrm{C}$ for 24 hours so that the moisture could be removed. The crucible, stirring paddle and sampler were all made of high-purity graphite material due to the strongly corrosive of the high temperature molten salts. And the special lid was prepared for preventing the 
molten salts from excessive volatilization. The high-purity argon was also needed to be put into the furnace to protect the equipment from oxidation. The furnace system of experiment was shown in Fig.1.

Table 1 Experimental reagents.

\begin{tabular}{|c|c|c|}
\hline Reagents & Purity (wt\%) & Manufacturer \\
\hline $\begin{array}{c}\mathrm{LaF}_{3} \\
\mathrm{NdF}_{3} \\
\mathrm{La}_{2} \mathrm{O}_{3} \\
\mathrm{Nd}_{2} \mathrm{O}_{3} \\
\mathrm{LiF}\end{array}$ & $\begin{array}{l}>99.9 \% \\
>99.9 \% \\
>99.9 \% \\
>99.9 \% \\
>99.9 \%\end{array}$ & $\begin{array}{l}\text { Grirem Advanced Materials Co.,Ltd } \\
\text { Grirem Advanced Materials Co.,Ltd } \\
\text { Grirem Advanced Materials Co.,Ltd } \\
\text { Grirem Advanced Materials Co.,Ltd } \\
\text { Sinopharm Chemical Reagent Co.,Ltd }\end{array}$ \\
\hline & $\frac{1}{0}$ & 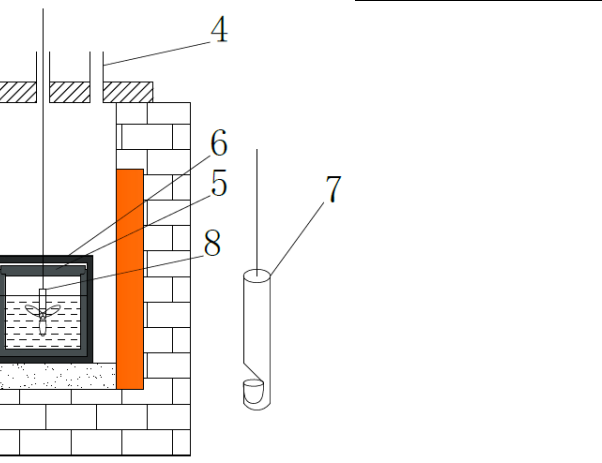 \\
\hline
\end{tabular}

Fig. 1 The furnace system of experiment

1-Temperature controller; 2-Thermocouple for Temperature control; 3-High temperature furnace; 4-Argon inlet; 5-lid; 6-Protective cover; 7-Sampler; 8-Stirring paddle

\section{Results and discussion}

Chemical titration is one typical laboratory method of quantitative chemical analysis that is used to determine the unknown concentration of an identified analyte. The determination of concentration of $\mathrm{REO}$ in $\mathrm{REF}_{3}-\mathrm{LiF}-\mathrm{REO}$ melts usually consists of three steps: preparation of samples for testing, samples dissolving in chemical reagents and chemical titration. However, due to the complex chemical reaction and limited solubility of REO in the $\mathrm{REF}_{3}-\mathrm{LiF}$ melts, excessively adds REO in melts will lead to the precipitation and even the slag of REOF [23]. So, the supernatant was taken after settling the melts for minutes which can ensure the solid-liquid separation. The samples dissolving in chemical reagents is a process that need to consume nitric acid, perchloric acid and so on. The $\mathrm{RE}_{\mathrm{w} t} \%$ of the supernatant could be calculated by the followed equation.

$$
R E_{\mathrm{wt} \%}=\frac{T \times V}{\mathrm{~W} \times 1000} \times 100 \%
$$

Where $\mathrm{W}$ is the mass of the sample in $\mathrm{g}$; $T$ is the titre of EDTA for $\mathrm{La}$ in $\mathrm{mg} / \mathrm{mL}, T=\mathrm{M} \times \mathrm{M}_{\mathrm{RE}}, \mathrm{M}$ is the molarity of EDTA, $\mathrm{M}_{\mathrm{RE}}$ is the atomic mass of RE; $V$ is the consumption of EDTA in $\mathrm{mL}$.

The isothermal and saturated method combining chemical titration has been used by researchers for studying solubility of REO in different rare earth fluoride melts. Wu et al [12] have researched on solubility of mish REO in LiF-BaF2-REF3 melts. They found that the solubility of REO was $2 \%$ wt$4 \%$ wt with the temperature ranged $900-1040^{\circ} \mathrm{C}$. $\mathrm{Hu}$ [11] has reported the solubility and dissolution rate of $\mathrm{Nd} 2 \mathrm{O} 3$ in $\mathrm{NdF} 3-\mathrm{LiF}-\mathrm{Nd} 2 \mathrm{O} 3$ melts. In present study, the changing law of RE concentration in 40mol\%REF3-60mol\%LiF (RE=La and Nd) melts with the continuously added REO was investigated by chemical titration analysis of the supernatant samples, and the results are shown in Fig 2. 

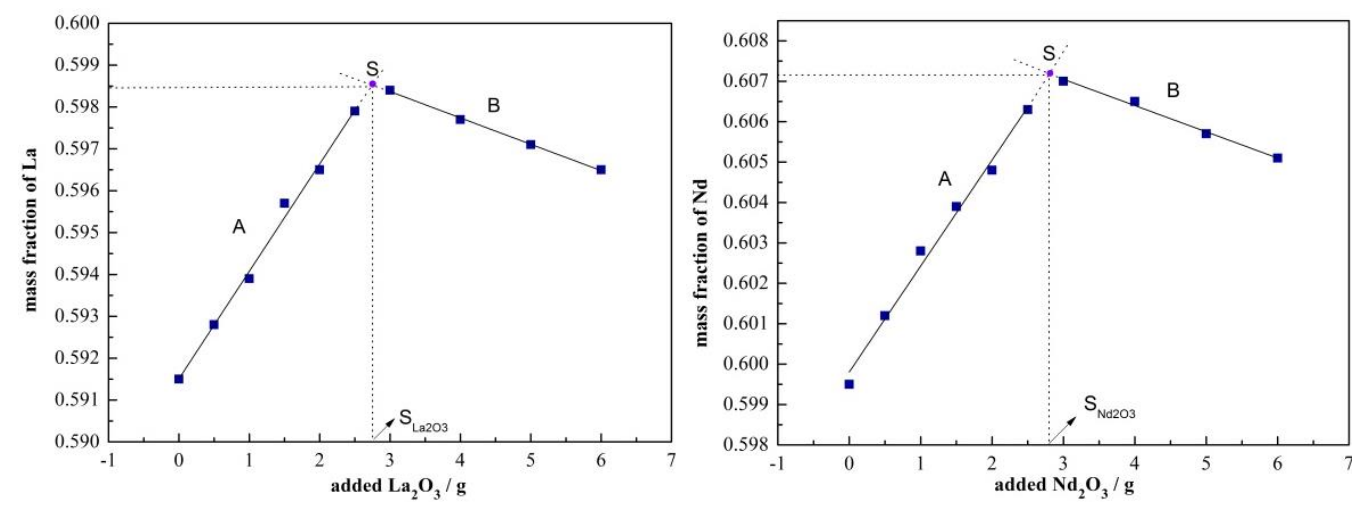

Fig. 2 Relationship between contents of RE and the added REO in the melts

From the Fig 2, one can easily find that the RE concentration linearly increased with the increasing REO and reached the maximum value at the solubility of REO, and then linearly decreased with the continuously adding REO. According to the experimental phenomena and previous references, the changing law was owing to the chemical reaction and relatively low solubility of REO in the melts. On the one hand, when the added $\mathrm{RE}_{2} \mathrm{O}_{3}$ was lower than solubility, all the added $\mathrm{RE}_{2} \mathrm{O}_{3}$ chemically reacted with melts to form REOF and then completely dissolved in the melts. On the other hand, when the added $\mathrm{RE}_{2} \mathrm{O}_{3}$ was higher than solubility, to add $\mathrm{RE}_{2} \mathrm{O}_{3}$ continuously not only didn't increase the concentration of $\mathrm{RE}$ ions but also reduce the content of $\mathrm{REF}_{3}$ by form of REOF sunk to the bottom according to references $[11,22,13]$. By linear fitting the curves in Fig. 2, one can easily identify that the curves can be thought of as having two sections: the increasing segment $A$ and the decreasing segment B. On the one hand, the fitting parameters of segment A and segment B can be used for calculation and finding intersection $\mathrm{S}$ between two line segments. Then, the abscissa value of intersection $\mathrm{S}$ represents the saturated solubility of $\mathrm{RE}_{2} \mathrm{O}_{3}$ in molten system at the definite temperature. On the other hand, the linear fitting of segment A and segment B can be considered as the standard curves and the parameters can be used for calculating REO concentration based on the measured values of RE concentration.

In present study, the REO concentration changing law in the practical electrolysis process of some electrolysis plant was measured by the method discussed above. Then the changing of REO concentration with the electrolytic time was investigated. The composition of the electrolyte was $40 \mathrm{~mol}_{2} \mathrm{REF}_{3}-60 \mathrm{~mol} \% \mathrm{LiF}$ ( $\mathrm{RE}=\mathrm{La}$ and $\mathrm{Nd}$ ), the cell voltage is $10.5 \mathrm{~V}$, and the electric current is about 4200 A. The measured results are shown in Figs. 3 and 4.

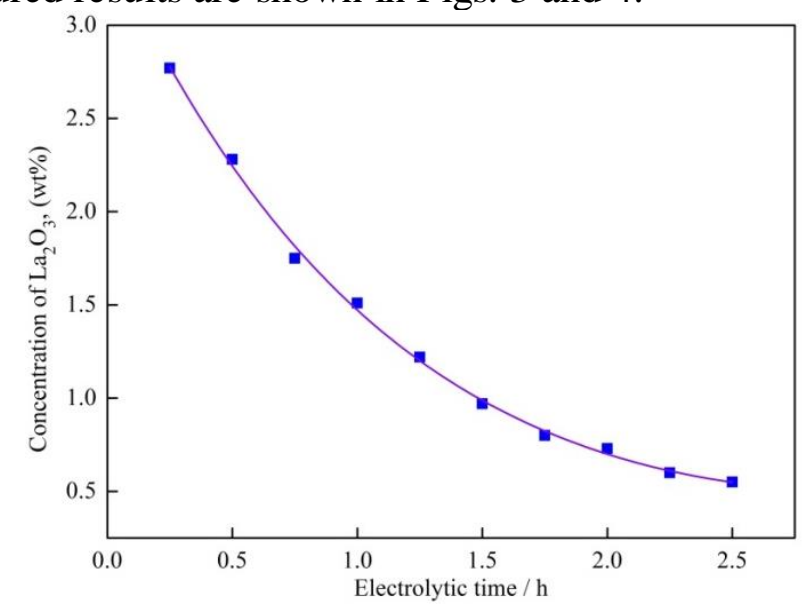

Fig. 3 Relationship between concentration of $\mathrm{La} 2 \mathrm{O} 3$ and electrolytic time 


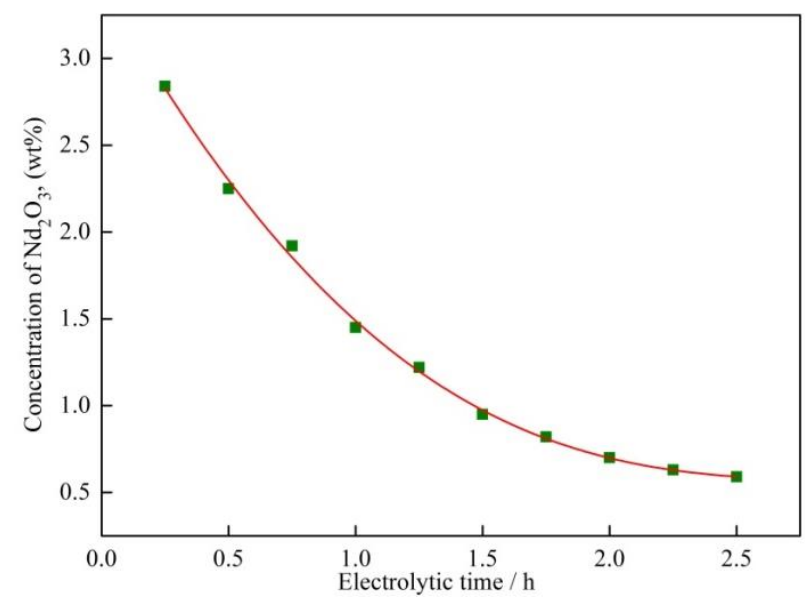

Fig. 4 Relationship between concentration of $\mathrm{Nd} 2 \mathrm{O} 3$ and electrolytic time

Figs. 3 and 4 show that the concentration of REO decreases with the electrolytic time, and rate of the decreasing also declines with the electrolytic time. According to the references [8-9], the current efficiency increases with the increasing of the addition rate of REO, which can be interpretation of higher REO concentration corresponding to higher current efficiency. So it is benefit of practical production to maintain a higher concentration of REO in the molten salts electrolyte. From the Figs. 3 and 4, it is also found that the REO concentration is relatively low (lower than 1\% wt) in the electrolyte when the electrolytic time reaches $1.75 \mathrm{~h}$. And the changing of REO concentration after electrolysis for $1.75 \mathrm{~h}$ is relative lower comparing to the values of before $1.75 \mathrm{~h}$. Based on the discussions above, this study recommend that the reasonable time interval of REO addition can define as $1.75 \mathrm{~h}$. At present, the empirical value of time interval of REO addition is usually defined as about $2 \mathrm{~h}$ in the practical production, which is close to the recommended value in present study. This would also illustrate the reliability of chemical titration method for determination of concentration of REO in $\mathrm{REF}_{3}-\mathrm{LiF}-\mathrm{REO}$ melts. The advantage of chemical analysis is that the determined result with high accuracy as well as high reliability. However, due to a great number of chemical reagents need to be consumed in the experimental process, the approach has disadvantages of uneconomic and enviorimentally unfriendly.

\section{Conclusion}

The melts with the composition of $40 \mathrm{~mol}_{\%} \mathrm{REF}_{3}-60 \mathrm{~mol} \% \mathrm{LiF}(\mathrm{RE}=\mathrm{La}$ and $\mathrm{Nd}$ ) was taken as object for illustrating the measurement of concentration and solubility of REO by the chemical titration method. And then the changing of REO concentration in $40 \mathrm{~mol}^{2} \mathrm{REF}_{3}-60 \mathrm{~mol} \% \mathrm{LiF}$ melts with electrolytic time in practical electrolysis production was studied.

1) The concentration and solubility of REO in $40 \mathrm{~mol}^{2} \mathrm{REF}_{3}-60 \mathrm{~mol} \% \mathrm{LiF}$ melts is relatively low. The chemical titration method on determination of concentration of REO in the melts is reliability.

2) The concentration of REO decreases with the electrolytic time, and rate of the decreasing also declines with the electrolytic time. And the reasonable time interval for REO addition was recommended defining as $1.75 \mathrm{~h}$ which is very close to the empirical value $2 \mathrm{~h}$.

\section{Acknowledgements}

The authors would like to express great appreciate to Financial support of Project (2011AA03A409) supported by the National High Technology Research and Development Program of China (863 Program); Project (N110202002) supported by the Fundamental Research Funds for the Central Universities, China. 


\section{References}

[1]. CHEN Dehong, YAN Shihong, LI Zongan, WANG Zhiqiang, PANG Siming, WANG Xiangsheng, XU Lihai. Liquid-cathode cell for neodymium electrolysis in NdF3-LiF-Nd2O3 molten [J]. Journal of the Chinese Rare Earth Society, 2009, 27(2): 302-305. (in Chinese)

[2]. WANG Wei, LI Zongan, WANG Zhiqiang, CHEN Dehong, ZHOU Lin. Fused salt electrorefining of lanthanum [J]. Chinese Journal of Rare Metals, 2013, 37(5): 770-777. (in Chinese)

[3]. CHEN Yu-xin. Research progress of preparation of rare earth metals by electrolysis in fluoride salt system [J]. Chinese Rare Earths, 2014, 35(2) : 99-107. (in Chinese)

[4]. LIN Weiqing, XIAO Zugao. Development of producing high-purity La-metal in fused-salt electrolysis process [J]. Jiangxi Nonferrous Metals, 2003, 17(1): 32-34. (in Chinese)

[5]. P. Taxil, L. Massot, C. Nourry, M. Gibilaro, P. Chamelot, L. Cassayre. Lanthanides extraction processes in molten fluoride media: Application to nuclear spent fuel reprocessing [J]. Journal of Fluorine Chemistry, 2009, 130 (1): 94-101.

[6]. M. Gibilaro, L. Massot, P. Chamelot, P. Taxil. Study of neodymium extraction in molten fluorides by electrochemical co-reduction with aluminium [J]. Journal of Nuclear Materials, 2008, 382 (1): 39-45.

[7]. P. Chamelot, L. Massot, C. Hamel, C. Nourry, P. Taxil. Feasibility of the electrochemical way in molten fluorides for separating thorium and lanthanides and extracting lanthanides from the solvent [J]. Journal of Nuclear Materials, 2007, 360 (1): 64-74.

[8]. Electrolysis departments of Baotou research institute for steel metallurgy. The preparation of metal neodymium by electrolyzing neodymium oxide in fluoride molten salts [J]. China Academic Journal Electronic Publishing House, 1974: 34-41.

[9]. Zhang Zhihong, Zhao Lizhong, Jiao Shizhuo, Wu Diwu. The study on producing metal lanthanum by electrolyzing lanthanum oxide [J]. Journal of Jiangxi nonferrous metals, 1992, 6(3): 129-134.

[10]. LIU Kuiren. The study on properties of molten salts and electrode processes of neodymium electrolysis [D]. Shenyang: Northeastern University, 2001. (in chinese)

[11]. HU Xianwei. Study on Ionic structure and its application of NdF3-LiF-Nd2O3 system Melts [D]. Shenyang: Northeastern University, 2009. (in chinese)

[12]. WU Wenyuan, ZHANG Jinsheng. The solubility of rare earth oxide in LiF-BaF2-REF3 melts [J]. Journal of Nonferrous Mining and Metallurgy, 2000, 16(6): 34-36.

[13]. Anne-Laure Rollet, Haruaki Matsuura, Catherine Bessada. An in situ spectroscopic study of the local structure of oxyfluoride melts: NMR insights into the speciation in molten LiF-LaF3Li2O systems [J]. Dalton Transactions, 2015, 44(2): 522-529.

[14]. M. Ambrová, J. Juriová, V. Danielik, J. Gabová. On The Solubility of Lanthanum oxide in Molten Alkali Fluorides [J]. Journal of Thermal Analysis and Calorimetry, 2008, 91(2): 569-573.

[15]. X. Guo, Jilt Sietsma, Yongxiang Yang. A critical evaluation of solubility of rare earth oxides in molten fluorides [J]. Rare Earths Industry, 2016, 223-234.

[16]. Pshenichny, R. N., Omelchuk, A. A. Interaction of rare-earth oxides with binary molten mixtures of zirconium and alkali metal fluorides [J]. Russian Journal of Inorganic Chemistry, 2012, 57(1): 115-119. 
[17]. Stefanidaki, E., Photiadis, G. M., Kontoyannis, C. G., Vik, A. F., Østvold, T. Oxide solubility and raman spectra of NdF3-LiF-KF-MgF2-Nd2O3 melts [J]. Journal of the Chemical Society Dalton Transactions, 2002, 11(11): 2302-2307.

[18]. Guo, X., Sun, Z., Sietsma, J., Yang, Y. Semiempirical model for the solubility of rare earth oxides in molten fluorides [J]. Industrial \& Engineering Chemistry Research, 2016, 55(16): 4773-4781.

[19]. M. Ambrová, J. Jurišová. Solubilities of lanthanum oxide in fluoride melts: part I. solubility in M3AlF6 (M = Li, Na, K) [J].Thermochimica Acta, 2006, 443(1): 105-108.

[20]. Reddy, R. G., Kumar, S. G. Solubility and thermodynamic properties of Y2O3 in LiF-YF3 melts [J]. Metallurgical and Materials Transactions B, 1994, 25(1): 91-96.

[21]. Guo, X., Sietsma, J., Yang, Y. Solubility of rare earth oxides in molten fluorides [C]. Eres2014: European Rare Earth Resources Conference, 2014, 149-155.

[22]. Zhu Xiaoping, Sun Shuchen, Lu Shuaidan, Huang Xiaoxiao, Li Kuanhe, Tu Ganfeng, Huang Xiaowei, Huang Shaodong. Surface tension of light rare earth fluoride molten salts electrolyte system [J]. Thermochimica Acta, 2016, 636: 42-47.

[23]. Zhao Yifa, Wang Ling, Liu Woyuan. Behavior of LaOF in molten salt during electrowinning of lanthanum [J]. Journal of the Chinese Rare Earth Society, 1987, 5(3): 25-30. 